\title{
Spontaneous rupture of metastatic $\alpha$-fetoprotein-producing gastric cancer of the liver
}

\author{
Tetsuro Sohda - Takayuki Hanano $\cdot$ Hisanori Miyamoto $\cdot$ Yoko Kitano · \\ Kaoru Iwata - Masanori Yokoyama - Makoto Irie - Yasuaki Takeyama • \\ Satoshi Shakado $\cdot$ Shotaro Sakisaka
}

Received: 22 October 2007/Accepted: 18 February 2008/Published online: 8 April 2008

(C) The Author(s) 2008

\begin{abstract}
An 80-year-old man was admitted to our hospital because of the rupture of the liver. Laboratory data showed iron-deficiency anemia, although there was no liver dysfunction. A computed tomography scan showed large liver tumor with intraperitoneal hemorrhage, and since a serum level of $\alpha$-fetoprotein (AFP) was extremely high, we initially suspected a rupture of hepatocellular carcinoma (HCC). Transarterial embolization was performed to stop bleeding from the tumor, followed by an endoscopic examination that revealed advanced gastric cancer. Histological analysis revealed that both the gastric and the hepatic tumors were moderately to poorly differentiated adenocarcinoma, as well as that both tumors were immunohistochemically positive for AFP. Finally, we diagnosed AFP-producing gastric cancer associated with liver metastasis. Rupture of metastatic liver cancer is rare, and accordingly, distinction from HCC is important, particularly for the cases of AFP-producing gastric cancer.
\end{abstract}

Keywords $\alpha$-Fetoprotein - Gastric adenocarcinoma . Spontaneous liver rupture

\section{Abbreviations \\ AFP $\alpha$-Fetoprotein \\ HCC Hepatocellular carcinoma \\ TAE Transarterial embolization}

T. Sohda $(\varangle) \cdot$ T. Hanano $\cdot$ H. Miyamoto - Y. Kitano .

K. Iwata $\cdot$ M. Yokoyama · M. Irie · Y. Takeyama ·

S. Shakado $\cdot$ S. Sakisaka

Department of Gastroenterology and Medicine, Fukuoka

University School of Medicine, 7-45-1 Nanakuma, Jonan-ku,

Fukuoka 814-0180, Japan

e-mail: tetsuro@fukuoka-u.ac.jp

\section{Introduction}

$\alpha$-Fetoprotein (AFP) is a well-known tumor marker for hepatocellular carcinoma (HCC). A type of gastric cancer has been identified to produce AFP [1]. AFP-producing gastric cancers have characteristics of an unusual clinical course, with events not seen in the cases of common gastric cancer such as rapid growth and easy metastasis to the liver [2]. We herein report a case of AFP-producing gastric cancer that resembled HCC owing to the complication of liver rupture.

\section{Case report}

An 80-year-old man was admitted to our hospital because of sudden and severe abdominal pain. He had no history of liver disease. Physical examination revealed tenderness at the right costal region.

The laboratory data showed no liver dysfunction. Markers for hepatitis viruses except for hepatitis B core antigen (anti-HBc) were all negative. As for tumor markers, serum levels of carbohydrate antigen 19-9 were slightly elevated. On the other hand, serum AFP level was extremely high at $21,090 \mathrm{ng} / \mathrm{ml}$. AFP analysis showed a broadband pattern of AFP, different from the typical pattern of HCC. The level of serum des- $\gamma$-carboxyprothrombin was normal (Table 1).

A computed tomography scan showed large tumor in the right lobe of the liver and fluid collection within the tumors (Fig. 1). The thickened gastric wall was also seen. Under the ultrasonographic guidance, rupture of a liver tumor was diagnosed on the basis of the collected bloody fluid. Emergency angiography revealed a huge hypervascular tumor in segment 6 of the liver, and 
Table 1 Laboratory investigations

\begin{tabular}{|c|c|c|c|}
\hline WBC & $10,000 / \mathrm{ul}$ & HBsAg & $(-)$ \\
\hline $\mathrm{RBC}$ & $337 \times 10^{4} / \mu \mathrm{l}$ & Anti-HBc & $(+)$ \\
\hline $\mathrm{Hb}$ & $9.6 \mathrm{~g} / \mathrm{dl}$ & HBV-DNA & $<2.6 \mathrm{LEG} / \mathrm{ml}$ \\
\hline \multirow[t]{2}{*}{ Plt } & $25.1 \times 10^{4} / \mu 1$ & Anti-HCV & $(-)$ \\
\hline & & HCV-RNA & $(-)$ \\
\hline T-Protein & $6.0 \mathrm{~g} / \mathrm{dl}$ & & \\
\hline Albumin & $2.8 \mathrm{~g} / \mathrm{dl}$ & AFP & $\begin{array}{l}21,090 \mathrm{ng} / \mathrm{ml} \\
\quad(\text { normal }<10)\end{array}$ \\
\hline T-Bilirubin & $1.4 \mathrm{mg} / \mathrm{dl}$ & DCP & $\begin{array}{l}26 \mathrm{mAU} / \mathrm{ml} \\
\quad(\text { normal }<40)\end{array}$ \\
\hline AST & $43 \mathrm{IU} / 1$ & CEA & $\begin{array}{l}3.4 \mathrm{ng} / \mathrm{ml} \\
\quad(\text { normal }<5)\end{array}$ \\
\hline ALT & $20 \mathrm{IU} / 1$ & CA19-9 & $\begin{array}{l}50 \mathrm{U} / \mathrm{ml} \\
\quad(\text { normal }<37)\end{array}$ \\
\hline $\mathrm{LDH}$ & $197 \mathrm{IU} / 1$ & & \\
\hline ALP & $278 \mathrm{IU} / 1$ & & \\
\hline$\gamma$-GTP & $99 \mathrm{IU} / 1$ & & \\
\hline
\end{tabular}

transarterial embolization (TAE) was immediately performed to control the bleeding from the tumor (Fig. 2).

Endoscopic examination performed on the following day revealed Borrmann III type advanced cancer at the cardiac region of the stomach (Fig. 3).

Gastric biopsy demonstrated moderately to poorly differentiated adenocarcinoma. In the histological section, hepatoid differentiation of cancer cells was not seen. In order to distinguish a metastatic lesion of gastric cancer of the liver from gastric cancer complicated with HCC, we also performed a biopsy of the liver tumor. The liver tissue showed moderately differentiated adenocarcinoma, resembling the gastric lesion, and both the gastric and the liver lesions were positive for AFP immunohistochemically (Fig. 4). We also confirmed the production of AFP in the cancer cells by reverse transcription polymerase chain reaction. Finally, we diagnosed AFP-producing gastric cancer together with liver metastasis.

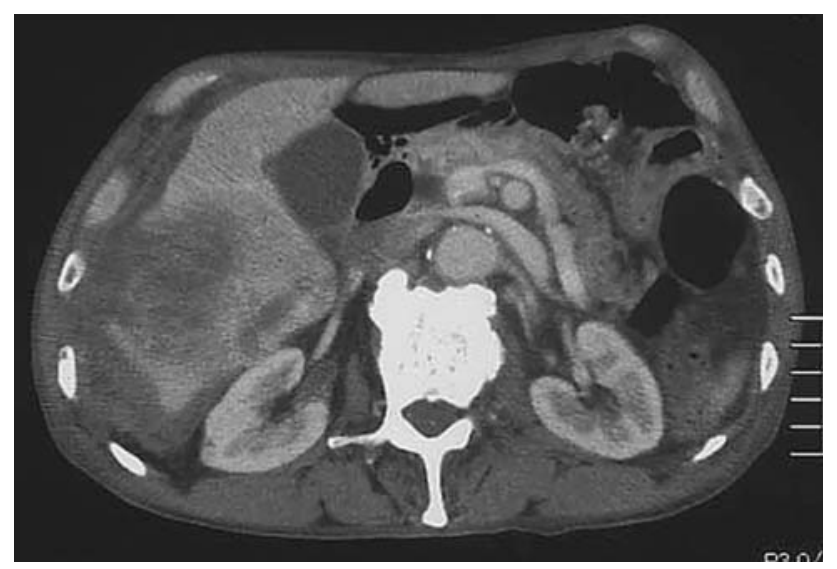

Fig. 1 A computed tomography scan showing large tumor in the right lobe of the liver and fluid collection within the tumor

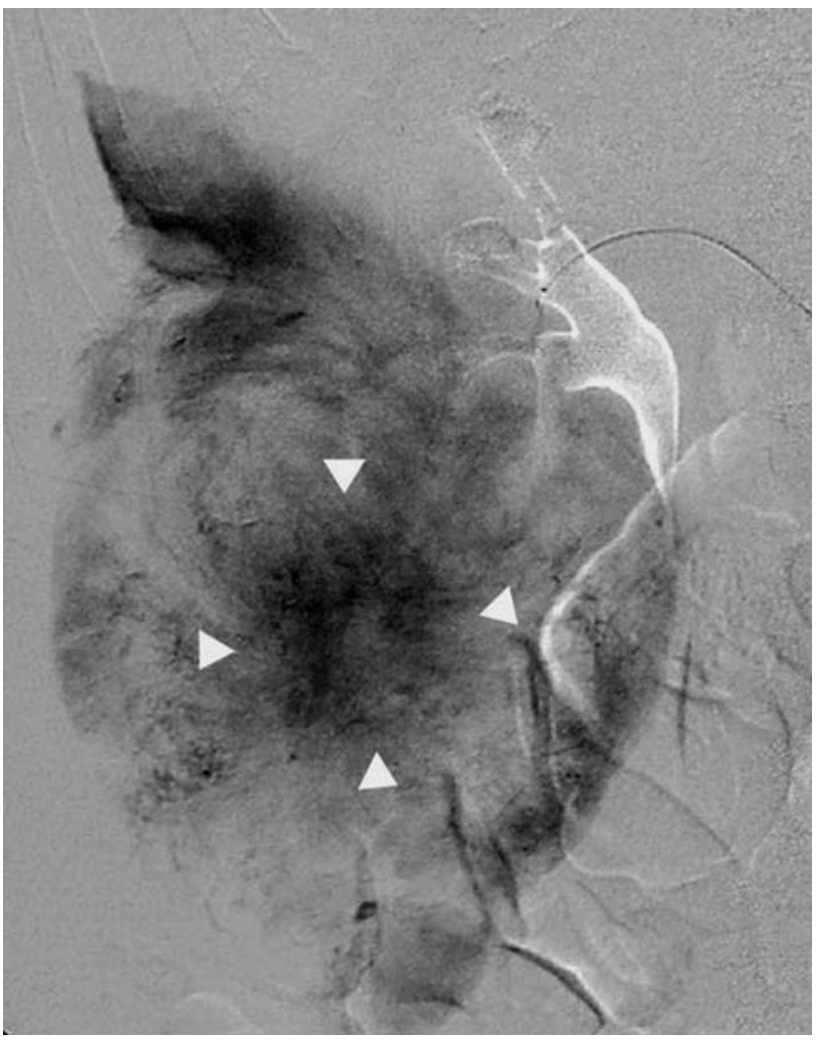

Fig. 2 Emergency angiography revealing a huge hypervascular tumor in segment 6 of the liver (arrow heads). Transarterial embolization was immediately performed to control the bleeding from the tumor

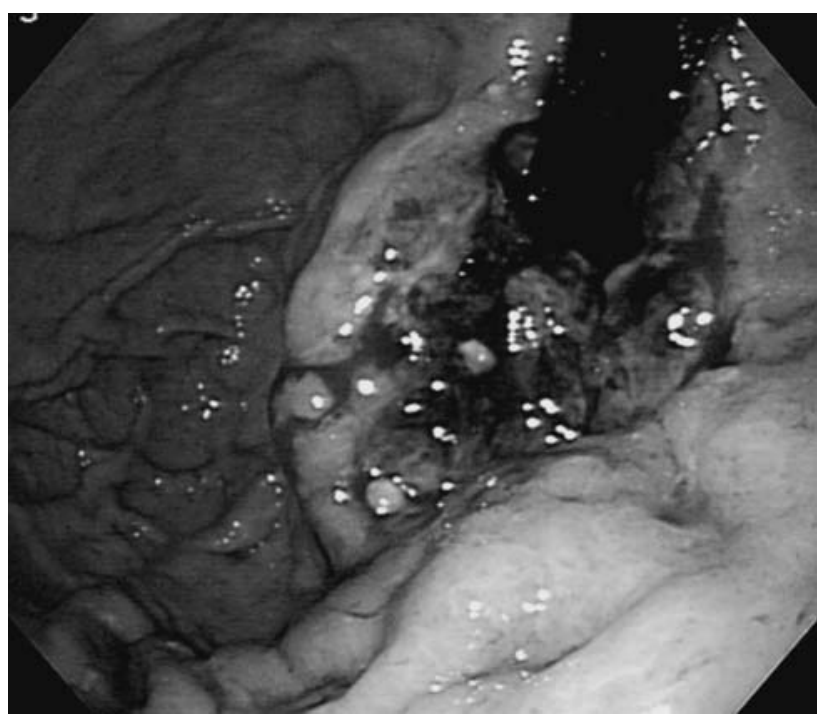

Fig. 3 Endoscopic examination, performed on the following day, showing Borrmann III type advanced cancer at the cardiac region of the stomach

TAE was able to completely control the tumor bleeding. However, the patient and his family refused further treatment, such as chemotherapy, and the patient was then transferred to another hospital for supportive care. 
Fig. 4 (a) Gastric tumor showing moderately differentiated adenocarcinoma. (b) The findings of the liver tumor resembled that of the gastric lesion. Both (c) the gastric and (d) the liver lesions were positive for AFP immunohistochemically


\section{Discussion}

$\alpha$-Fetoprotein-producing gastric cancer is relatively rare, and a metastatic liver lesion from such cancer is often difficult to discern from HCC through a differential diagnosis. The present case was in fact a case of spontaneous rupture of AFP-producing gastric cancer of the liver. It should be noted, however, that we had initially suspected HCC rather than metastatic liver cancer up until the results of endoscopic examination.

Spontaneous liver rupture is sometimes seen in the cases of HCC; however, it is rare in other liver tumors. Rupture of metastatic liver cancer is also uncommon [3]. It may result from insufficient blood supply to the tumor. However, details of the mechanism for spontaneous liver rupture have remained obscure.

A report of liver rupture in AFP-producing gastric cancer similar to the present case has been previously reported [4]. Angiography demonstrated that the ruptured liver tumor was a hypervascular tumor as well. This finding resembles with that seen in HCC. AFP-producing gastric cancer is known to show rapid growth and invasion to small vessels [5]. In addition, hypervascularity may be associated with spontaneous tumor rupture.

Rupture of the tumor is one of the life-threatening complications. Mortality of patients with ruptured HCC in the acute phase remains high [6]. Some reports have recommended selective hepatic artery ligation or emergency hepatectomy as the treatments of choice in patients with limited tumors [7]. Recently, TAE has been chosen in many patients with ruptured HCC. Development of TAE technique has improved the prognosis of patients with ruptured HCC [8].

Particularly in this case where the patient suffered from AFP-producing gastric cancer complicated by liver rupture and positive findings for serum $\mathrm{HBc}$ antibody, the distinction from HCC was critically important. Positivity for $\mathrm{HBc}$ antibody sometimes suggests occult $\mathrm{HBV}$ infection associated with other risk factors of HCC in several liver diseases, including cryptogenic cirrhosis and chronic hepatitis C [9].

The patient in the present case did not wish to receive any further treatment because there are no established chemotherapy regimens for AFP-producing gastric cancer. The prognosis of AFP-producing gastric cancer has been reported to be very poor. Furthermore, most of these cases show resistance to anticancer drugs. Recently, S-1, a novel oral derivative of 5-fluorouracil, was developed, and its effectiveness against advanced gastric cancer has been reported [10]. Its effect against some cases of AFP-producing gastric cancer has also been reported; however, further investigations are called for with regard to the treatment of AFP-producing gastric cancer.

Acknowledgments The authors thank Miss K. Miller (Royal English Language Center, Fukuoka, Japan) for English text revision as used in this article. 
Open Access This article is distributed under the terms of the Creative Commons Attribution Noncommercial License which permits any noncommercial use, distribution, and reproduction in any medium, provided the original author(s) and source are credited.

\section{References}

1. Matias-Guiu X, Guix M. Hepatoid gastric adenocarcinoma. Pathol Res Pract 1989;185:397-400.

2. Chang YC, Nagasue N, Abe S, Taniura H, Kumar DD, Nakamura T. Comparison between the clinicopathological features of AFPpositive and AFP-negative gastric cancers. Am J Gastroenterol 1992;87:321-5.

3. Kiyak G, Özer M, Gürer A, Devay A, Yazgan A. Hemoperitoneum secondary to spontaneous rupture of metastatic gastric leiomyosarcoma of the liver: report of a case. Turk J Gastroenterol 2006;17:120-2.

4. Yoshida H, Mamada Y, Taniai N, Mizuguchi Y, Nakamura Y, Nomura T, et al. Ruptured metastatic liver tumor from an alphafetoprotein-producing gastric cancer. J Nippon Med Sch 2005;72: 236-41.
5. Nagai E, Ueyama T, Yao T, Tsuneyoshi M. Hepatoid adenocarcinoma of the stomach. A clinicopathologic and immunohistochemical analysis. Cancer 1993;15(72):1827-35.

6. Chen CY, Lin XZ, Shin JS, Lin CY, Leow TC, Chen CY, et al. Spontaneous rupture of hepatocellular carcinoma. A review of 141 Taiwanese cases and comparison with nonrupture cases. J Clin Gastroenterol 1995;21:238-42.

7. Cherqui D, Panis Y, Rotman N, Fagniez PL. Emergency liver resection for spontaneous rupture of hepatocellular carcinoma complicating cirrhosis. Br J Surg 1993;80:747-9.

8. Okazaki M, Higashihara H, Koganemaru F, Nakamura T, Kitsuki $\mathrm{H}$, Hoashi $\mathrm{T}$, et al. Intraperitoneal hemorrhage from hepatocellular carcinoma: emergency chemoembolization or embolization. Radiology 1991;180:647-51.

9. Tanaka K, Nagao Y, Ide T, Kumashiro R, Sata M. Antibody to hepatitis $\mathrm{B}$ core antigen is associated with the development of hepatocellular carcinoma in hepatitis $\mathrm{C}$ virus-infected persons: a 12-year prospective study. Int J Mol Med 2006;17:827-32.

10. Osugi H, Takada N, Takemura M, Kaseno S, Lee S, Ueno M, et al. Oral fluoropyrimidine anticancer drug TS-1 for gastric cancer patients with peritoneal dissemination. Oncol Rep 2002;9: 811-5. 